\title{
ARE VARIABLE ANNUITIES THE ANSWER TO INFLATION?
}

\author{
Paul W. McCracken \\ University of Michigan
}

THE MAJOR REASON for interest in variable annuities stems from the possibility that they would provide one answer to the problem of hedging against price inflation. Two questions are, of course, involved. Would these, in fact, provide a reasonably adequate hedge against inflation? Is the prospect for chronic price inflation serious enough to warrant this substantial departure from financial orthodoxy?

The issues involved in this first question have been at the focus of many discussions in the financial community. Two or three conclusions seem obvious. Funds invested in fluctuating-price assets will provide substantially more of a hedge against inflation than those invested in more orthodox ways. The hedge is not perfect, and individual situations could certainly arise where the results would work out badly. Stock prices and the cost of living do move conversely at times. The timing of benefit payments may be adverse. The selection of individual securities may be sufficiently unfortunate so that a portfolio might behave worse than stock averages.

These are, however, questions which must be explored by those closer to the specific problems which the financial industry might face if it were to move actively in this direction. My comments here will be largely confined to the second question, i.e., what are the longer-run price-level prospects? This, of course, is a fundamental question, and how it is answered importantly determines whether these other matters are academic or real-life considerations.

II

In the considerable amount of postwar discussion of price-level prospects, six reasons have emerged for expecting that we are in an "age of inflation," with the long-run trend of the dollar's purchasing power declining. ${ }^{1}$

1. The phrase is from a series of articles on "Agenda for the Age of Inflation" beginning in the Economist (August 18, 1951). Much of the material in this section appeared in an article "Is Price Inflation Inevitable?" Michigan Business Reviev (September, 1955). 
1. The longer-run history of the price level itself suggests this prospect. A chart of wheat prices in England, developed by Warren and Pearson, shows a rising trend from 1500 to about 1800, at which time wheat prices were ten times the level roughly three centuries earlier. ${ }^{2}$ This chart suggests that the declining price-level trend of the nineteenth century was, like the one for a century following 1650 , an interim reversal of a rising trend.

More recent trends are even more disturbing. The price level in this country has been demonstrating an entirely new resistance to downward pressure. After other major wars the price level declined substantially and (with the exception of World War I) regained the prewar level. By 1816 the price level was below 1812 ; and by 1879 it was below $1861 .^{3}$ Even after World War II the price level stabilized at roughly one-fifth below the 1920 peak. ${ }^{4}$

This contrasts sharply with our experience after World War II. There has been no "postwar decline," and even in the two postwar recessions, the price level was remarkably unresponsive to downward pressures. During the 1949 recession the wholesale price index declined 4 per cent, and in 1954 about 1 per cent. And the consumer price index for the recession year of 1954 averaged slightly higher than 1953.

The experience in other countries is even more striking. Since 1948, apart from a few exceptions (e.g., Belgium, Switzerland, and West Germany), most countries have experienced continued price rise greater than in the United States.

2. The great over-riding political and social objective of full employment is also felt by many to be inflationary. For one thing, it would suggest that we would not get the recession which would undo the price increases of the prior boom. Thus the price trend, and perhaps also business conditions generally, would resemble a stairstep pattern-rises during prosperities interrupted by intervening horizontal movements.

One problem here is the argument that is certain to develop about how full employment must be to be full. Employment in 1955, for

2. George F. Warren and Frank A. Pearson, Gold and Prices (New York: Wiley, 1935), p. 438.

3. According to the wholesale price index. The cost-of-living index of the Federal Reserve Bank of New York after the Civil War never dropped back to the 1861 level. At the low point (1894-95) the index remained 16 per cent above the 1861 level. Cf. Historical Statistics of the United States, 1889-1945 (Washington, D.C.: Bureau of the Census, 1949), pp. 234-35.

4. As measured by the consumer price index. The more volatile wholesale index stabilized at 35 per cent below 1920 . 
example, will average about three million over 1954; the length of the work week in manufacturing will exceed the 1950-52 average; and unemployment is estimated at just over 3 per cent of the labor force. Yet the question has been raised about whether the recovery from 1954 has been adequate. One result of all this could be to put the economy under forced draft to the point of generating real inflationary pressures in order to eliminate unemployment which does not actually exist.

3. A slowly rising price level would have certain advantages. It would, for example, permit a larger output. Even at relatively high levels of output, production can usually be stepped up more by putting the economy under a bit of forced draft. Even if this produces inflationary pressures, it would obviously mean more output. Since the amount of real output produced is a better measure of the economy's contribution to welfare than movements in the price index, putting the economy under pressure to produce at absolute capacity rates (even at the cost of some inflation) would seem to be in line with our economic welfare. This is the view which Professor Hansen developed earlier this year in testimony before the Joint Congressional Committee on the Economic Report.

4. A certain amount of inflationary pressure has been "built in" to our economy. An obvious illustration has to do with the automatic escalators incorporated into many labor cntracts. In theory these provisions need not be inflationary. In practice they are apt to be.

One of the "escalators" provides for automatic increases in wage rates for the estimated increase in the nation's productivity or output per man hour. But this is not a completely unambiguous concept, and there can be and are differences about how to measure this and what the results are. Where such differences exist, it is almost inevitable that union negotiators are going to press for a figure on the high side of the probable range.

Moreover, a part of the aggregate improvement in productivity arises out of a shift from low to high productivity industries. With such a shift, the nation's output per man hour increases even if productivity within each line of industry were to remain constant. If then wage rates are escalated upward by the increase in over-all productivity, cost levels must obviously rise. ${ }^{6}$ According to $\mathrm{Mr}$.

5. Alvin H. Hansen, "Economic Growth and Inflation," Commercial and Financial Chronicle (February 24, 1955), p. 20.

6. Cf. Jules Backman, "Wage-Productivity Comparisons," Industrial and Labor Relations Review (October, 1954), pp. 49-67. 
Kendrick, whose figures have been widely quoted, output per man hour has increased 2.1 per cent per year in the private economy, of which 0.27 per cent was accounted for by the farm-to-non-farm shift of the labor force.

Even cost-of-living escalation may be inflationary, if at the time escalation is adopted prices are out of equilibrium (on the low side) relative to costs. The subsequent upward adjustment of prices to costs would then trip off a rise in wages rates, another rise of prices, etc. Furthermore, differences of opinion can arise as to whether orthodox price indexes are accurately reflecting "true" price-level movements. With wage rate changes now based in part on movements in these indexes we must certainly expect recurring arguments about whether these indexes are understating cost of living changes.

5. The major reason for concern about the long-run price level, of course, has to do with whether annual "rounds" of wage increases will be too large to be compatible with stable costs and prices. Overall productivity is generally assumed to be improving at the rate of 2 to 3 per cent per year. If labor contracts result in wage increases substantially in excess of this figure, persistent upward pressure on cost-price levels will be the result. ${ }^{8}$ We must then make a hard choice between a persistent deterioration in the purchasing power of the dollar or sufficient unemployment to neutralize the power of organized labor to exact these increases.

Our postwar experience is somewhat less than reassuring on this matter. Since 1946 hourly earnings in manufacturing have risen at the rate of 6.2 per cent per year, at least double the rate at which productivity is assumed to be increasing. ${ }^{9}$ And negotiations in 1955 have produced new contracts calling for an increase of roughly 10 per cent in some key industries. Here clearly is a major new force in the American economy.

6. Curiously, one of the more obvious and important reasons for concern about the long-run price level is one of the less frequently

7. John W. Kendrick, "National Productivity and Its Long-Term Projection" in Long-Range Economic Projection (National Bureau of Economic Research, 1954), p. 94. The farm-to-non-farm shift accounts for only a part of the inter-industry shift dimension. The 2.1 per cent is derived from a trend for the years 1909-41, but the trend fits postwar years reasonably well.

8. A particularly careful exploration of this whole problem can be found in Sumner $H$. Schlichter, "Do Wage Fixing Arrangements in the American Labor Market Have an Inflationary Bias?" American Economic Review (Proceedings, May, 1954), pp. 322-45.

9. And the rise in total wage costs per hour has undoubtedly been somewhat greater than this because of the relatively greater incidence of fringe benefits. 
mentioned-the possibility of war, or at least recurring military operations on a limited scale. Most major price inflations in this country have been associated with wars. The Korean military operation produced a 15 per cent permanent increase in the American price level.

What the nature of these matters may be in the future may well be no clearer to financial people than it apparently is to those in the diplomatic or military professions. What is clear is that financial policies based on the assumption that wars shall be no more are a little less than completely realistic.

\section{III}

In spite of the very persuasive case which can be made for the view that a rising price level is inevitable, the case is not completely established. There are some things to say on the other side.

1. The history of prices is not, I think, particularly conclusive. In the nineteenth century the price-level trend was down, as it was in the seventeenth century. Price movements are the resultant of pricemaking forces. An analysis of the way these forces will probably work themselves out in the future gets us closer to answering the question about price-level prospects than assuming that the future will reproduce the patterns of the past.

2. The power-of-organized-labor argument is admittedly a strong one. The "excessive" wage increases in the postwar period do not, however, prove the case. Unions were themselves negotiating in an inflationary environment. This meant for them two things. They were under rank-and-file pressure to recoup purchasing power being lost by price inflation. And the ease with which businessmen knew they could pass along cost increases in the form of higher prices moderated correspondingly any inclination to resist large wage demands. Professor Morton has pointed out that unions are obviously always going to be pressing for large wage increases. How much they get will depend importantly on management's appraisal of the ease with which pressures on profits from increased costs can be relieved by higher prices. And this depends importantly on whether purchasing power generally tends to be excessive, on fiscal and monetary policy.

Or, to use Professor Friedman's apt figure of speech, the postwar period does not tell us to what extent unions were the thermometer registering the heat or the furnace producing it. Would unions press for "excessive" wage increases even if it were known that fiscal and 
monetary policy would hold firm and unemployment would result? Or how strong would management's resistance to "excessive" wage increases be if they felt they could not be sure of relieving the pressure on profits by an increase in prices? The answers to these questions are by no means certain.

3. The advantages of a slowly rising price level are apt to be more apparent than real. It is doubtful, it seems to me, if persistent price inflation in the United States would contribute much to international financial equilibrium. The net result would be, in all probability, an even greater price inflation within other major countries, with differential rates of price-level movements continuing to pose exchange problems.

More importantly it is doubtful if it would mean more output and a higher standard of living in the long pull. An economy under forced draft is an economy of labor shortages, labor hoarding, and a tendency for the marginal productivity of labor to decline. And the easy markets produced by such inflationary conditions correspondingly reduce pressures for cost-reduction measures, new product development, and market and product research generally. There are many illustrations of where improved products and retooling with better equipment were forced by the demise of the inflationary markets.

Undoubtedly by putting the economy under forced draft the immediate result can be some increase in output. But this may come at the expense of slowing down those forces which work for rising productivity and living standards in the long run.

4. It seems quite unrealistic to think that a slowly rising price level can be kept slowly rising for very long, once it is assumed to be a part of public policy. A major adverse dividend of price inflation is the injustice of its uneven impact on different groups. And the gains and losses do not correspond very closely to the relative importance of the contributions being made to economic activity. There is sufficient sensitivity to this problem of equity so that an age of inflation would quickly produce demands for ways to assure that the economic position of different groups would not be worsened. Indeed during the last decade we have had proposed, from eminently responsible sources, price escalation for wages, Series $E$ bonds, pensions, depreciation charges, annuities, etc.

Such widespread price-level escalation would certainly produce one of two results. These escalators might result in a more and more rapid inflation. The rise in the price level during an inflation is, of 
course, nature's way of extinguishing excess purchasing power. But if the process of extinguishing the excess purchasing power sets in motion machinery to restore the extinguished purchasing power, through generalized price escalators, a price level which starts out rising slowly will rather quickly pick up speed. That this is so may, of course, lead to the opposite result-arrangements where no one loses (or gains) position by price inflation might stiffen public support of basic policies needed to avoid inflation.

\section{IV}

These considerations lead me to certain conclusions about the question we are considering at this session of our Association meetings.

1. The best objective of public policy remains a stable price level. The advantages of a slowly rising price level are most apt to be gained when there is public fear of a deflationary trend. The immediate postwar period is a classic illustration of this situation where a price inflation was inevitable, accompanied by pretty general depression-mindedness. One dividend from that whole experience was a sharpened sensitivity to the problems inflation produces, and for measures to relieve these problems. An orderly, continuous rise in the price level in short is quite improbable.

Moreover, whatever the short-run gains in output from putting the economy under pressure, the longer-run result would be a reduction in the vitality, flexibility, and capacity for growth of the economy. An economy always operating at the absolute top of its physical capacity is not apt to be the one making most rapid progress through time.

2. But the problem faced by the financial community is not only, or even perhaps primarily, what the nation's price-level policy ought to be. For planning purposes, a more pressing question has to do with what the price level will actually do. And the reasons for expecting an upward trend in the price level are substantial-the probability of recurring military operations; the size of annual wage increases; the public pressures not for inflation but for programs which produce inflation as a side effect. It seems clear, therefore, that the financial community cannot avoid asking what the implications for it are of a potentially inflationary economy.

If there should arise general concern about the future of the price level, the financial community would have no alternative but to endeavor to offer assets less exposed to loss of purchasing power 
from infiation. The reason is simply that there would be fewer takers for conventional insurance policies, pensions, annuities, bonds, and other financial instruments, which achieved orthodoxy during an era when the purchasing power of the dollar could be assumed to be relatively stable in the long run. Therefore, the price of staying in business would be to offer to customers the kinds of instruments and obligations which would seem to meet the needs of the times.

Moreover, financial institutions have not only a selfish interest in the matter but also a social responsibility for entrepreneuring new ways to assure their customers' financial position in real terms. The need for an adequate provision for retirement or for death and disability protection will be no less in an inflationary era. It is equally clear that currently orthodox ways of handling these problems would not then be adequate if we could no longer depend on the value of the dollar. If new ways of dealing with these problems become imperative, financial institutions must provide the leadership in working them out for the very obvious reason that leadership can hardly be expected from any other source.

But the questions are, of course, formidable. The basic requirement is that promises to pay currently stated in dollars must be restated in terms of real purchasing power. Here some difficult questions arise and no good purpose is served by pretending they do not exist.

Any price-level escalator would presumably need to work both ways. Would people understand this during a short-run price decline-which might well occur even on a long-run upward trend? Obviously a major educational problem would be involved. Yet how could this be undertaken without being guilty of a program to undermine further confidence in the value of money?

Maintaining the purchasing power of a pension or insurance policy might roughly be accomplished by adding an escalator providing for adjustments according to changes in the consumer price index. ${ }^{10}$ But how could a financial institution be sure they could live with such a changing and uncertain liability?

A possible compromise would be the investment of funds in something like common stocks with the commitment to vary out-payments tied to the behavior of assets. ${ }^{11}$ This involves the assumption

10. It is obvious, however, that the greater the number of people who have a financial stake in proving that price rise has already occurred, the greater will be the pressures on the index computers to deviate from rigid technical standards-in order to prove that the inflation has already taken place, which would justify an upward revision in pensions, etc., which would create further inflationary pressures.

11. As in the C.R.E.F, of the T.I.A.A. 
that the value of these assets will fluctuate with the cost of living. This looks like a reasonable assumption (at least so long as it does not become too general practice), but it is only an assumption.

My own guess is that if price-level problems become acute, pension programs will need to couple a pay-as-you-go supplement to the regular funded pension. And ways of doing this ought to be explored for insurance programs also, although $I$ have no competence in these technical matters and do not propose to offer any advice.

3. The vexatious questions raised when we try to think through the problem of hedging against inflation lead to only one conclusion. The best approach is to see that the problem does not arise-that a persistent erosion of the dollar's purchasing power does not take place. Otherwise the basic functions which financial institutions are designed to perform will inevitably suffer a loss of public esteem. A basic social function of our financial organizations is to facilitate thrift and the use of savings. Since savings and thrift would become less attractive with great uncertainty about their future value, even ingenious devices for adapting to inflation would only imperfectly do the job.

The financial community, it seems to me, has been too complacent about the possibility of an age of inflation-on the theory perhaps that "our liabilities are also in dollars." It is apparently not always clearly perceived that if we are in for a period of persistently rising prices the balance sheet may well be "safer" than the very life of the industry itself.

Therefore, the financial community's first attack on the problem of inflation should be at the source, vigorous support of strong public policies to preserve a reasonably stable dollar. Measures to make the existence of price inflation more palatable, essential as they may be, are not the basic answer for the financial community. 